\title{
Chapter 15 \\ Methodological and Ethical Dilemmas in Research Among Smuggled Migrants
}

\author{
Ilse van Liempt and Veronika Bilger
}

\subsection{Introduction}

The following contribution reflects on important methodological and ethical concerns when considering fieldwork with individuals considered to be vulnerable and hard to reach. As an example, we point to challenges when conducting fieldwork with smuggled migrants in The Netherlands and Austria (Bilger et al. 2006; van Liempt 2007) and while supervising other fieldwork studies dealing with smuggled migrants in Canada (van Liempt and Sersli 2013), in Lebanon, Pakistan, Macedonia, Bulgaria, Serbia and Hungary (Optimity Advisors, ICMPD, ECRE 2015) and in Turkey and Greece (Zijlstra and van Liempt 2017). When we started our empirical research in 2002, the literature on human smuggling only offered two discourses: the economic (Salt and Stein 1997) and the criminal (Chin 1999; Schloenhardt 2001). Today, there is much more variety. There are studies looking into the role of social networks in human smuggling (e.g. Antonopoulos and Winterdyk 2006; Herman 2006; Staring 2004; Zhang 2008), the human rights perspective is getting more attention (e.g. Bhabha 2005; Gallagher 2002; Morrison and Crosland 2001; Nadig 2002; Obokata 2005) and there are studies looking into gender dynamics within smuggling processes (Ahmad 2011; Donato et al. 2008; Peixoto 2009; Sanchez 2015; Schrover et al. 2008; Zhang et al. 2007). Overall, much more emphasis is put nowadays on migrants' experiences and perspectives than when we started

This is an updated version of Chapter 5 in Bilger and van Liempt (2009).

I. van Liempt $(\square)$

Utrecht University, Utrecht, The Netherlands

e-mail: I.C.vanLiempt@uu.nl

V. Bilger

The International Centre for Migration Policy Development (ICMPD), Vienna, Austria

e-mail: Veronika.Bilger@icmpd.org 
our research in 2002. At the time we were among the first to collect data on understanding human smuggling processes with smuggled migrants in Europe.

For a considerable time, our research project did not find support or funding because of the method we envisioned. It was doubted whether conducting interviews would result in accurate and sufficient information on the characteristics of an 'illegal' business such as human smuggling — and smuggled migrants were assumed to be incapable of providing insights into the social organisation of human smugglers and the smuggling organisations which had taken them to Europe. It was argued that they would never openly talk with researchers about sensitive issues such as human smuggling. Lee (1993) argues that studies into sensitive topics reveal questions around the kinds of research that are regarded as permissible in society and the ability of the powerful to control the research process.

In the end we succeeded in convincing the funding body and some of our colleagues of the importance of interviewing migrants who had, themselves, gone through the experience of being smuggled. Through exploring their knowledge, experiences, evaluations and strategies, we were able to nuance stereotypical beliefs and common knowledge on human smuggling processes-something which is vital.

Today, more empirical research is conducted with affected migrants (both from an academic point of view, as well as in policy reports: see, for example, Optimity Advisors, ICMPD, ECRE 2015; UNODC 2011), which is important both because the way in which the persons involved talk about their own experiences might reveal interesting discrepancies in regard to pictures portrayed in public discourse (see also Cornelius 1982; Liamputtong 2007) and because it allows us to explore the perspective from within and to gain the depth and quality of information needed to provide a realistic picture of certain migration processes, causes and dynamics. This, of course, applies not only to irregular migration or human smuggling but to all research exploring vulnerable individuals' perspectives. Such an approach, however, entails very particular methodological and ethical considerations and demands specific sensitivity and accuracy (Duvell et al. 2008; Lee 1993; Liamputtong 2007; Mauthner et al. 2002; van den Hoonaard 2002).

\subsection{Migrants' Own Perspectives}

As many asylum-seekers had been smuggled at some time in their migration process, we initially started to look at asylum application interviews or protocols of asylum hearings. However, as the purpose of these interviews is to decide on whether or not a person qualifies as a refugee as defined in the 1951 Geneva Refugee Convention, data collected by asylum authorities mainly contain information on the reasons for seeking asylum and the motives for leaving a country. Some attention is, however, also paid to modes of travel and routes taken but these data are less detailed. Still, when such data are at all accessible, the major problem when using them for researching individuals' migration processes is the setting in which the 
information is provided. The way in which this information is collected has an effect on the quality and reliability of these data. The applied techniques of interrogation are inter alia targeted to find inconsistencies within flight biographies. An example of the kind of pressure and its possible consequences which asylum-seekers may experience was provided by an Iraqi woman who was interviewed in The Netherlands:

I had the feeling they wanted me to make the story simpler than it was. I constantly had the feeling I was forgetting important details. And the most horrible thing was when I talked about painful events - they did not want to know how it must have been for me. They said they had enough information now. They did not even comfort me.

While this example shows that this kind of interview favours especially those able to express themselves in a clear way, it also shows that interviewees are afraid of not providing the 'right' information and therefore of lacking substantial grounds for asylum. As the applicants' narrations will be used for a negative or positive decision on their application for asylum, this might easily lead to the concealment of details or to 'adjustments' in respondents' own narrated flight biographies.

Another often-revealed example was the negative experiences people had with official interpreters translating their flight stories for the authorities. Some of our research participants emphasised that, now that they spoke some Dutch or German, they were shocked about how their interviews had been translated. Issues that were of real importance to them were communicated as if they were minor details, while other things were blown up out of proportion so that they themselves sensed that they had lost control over presenting and interpreting their own lives (see also Doornbos 2003). In order to get an insight into flight stories not produced under such pressure, we decided to look at narrations collected by civil society organisations legally assisting or accommodating asylum-seekers. Regardless of the fact that these stories were most probably conducted in a less-interrogative way, they were, nevertheless, also collected mainly for the organisations' own purposes. Hence, these documentations were also incomplete in respect to our research question. Besides, the organisations we contacted emphasised that, as asylum-seekers might not be familiar with the role of these organisations (whether they are part of the asylum system or not) and, in their bid to receive asylum, may be unclear as to what to talk about and what not to talk about. After reviewing these data sources and the respective available data, we were even more encouraged to conduct interviews ourselves in order to gain insights into the specific phenomenon of human smuggling. However, it was clear that the issues addressed above would also affect our work. Why would an asylum-seeker talk less attentively and carefully to a researcher than with an immigration officer, a translator or any other 'public' person?

This chapter deals with methodological and ethical questions around research involving vulnerable migrants, with a particular focus on the interlinked flows of irregular migration, human smuggling and refugee migration. It will address issues such as gaining access, building up trust, and reciprocity. However, when touching upon 'illegal' or semi-legal activities —as is the case in the above-mentioned fields_-ethical questions also clearly need to be addressed. 


\subsection{Ethical Issues}

For a long time, ethical issues relating to research that involved human subjects were limited to the field of medical studies (Duvell et al. 2008; Mauthner et al. 2002). The first international code of ethics to protect the right of people from research abuse was drawn up in 1949 as part of the Nuremberg Code. Other Codes of Ethics are the 'Declaration of Helsinki' (1964) and the 'Belmont Report' (1978). More recently, the European Commission funded the RESPECT project with the aim of developing standards more particularly for socio-economic research in the European Union. The project has developed a Code of Conduct for carrying out research in the social sciences based on a synthesis of the contents of a large number of various existing professional and ethical codes of practice. However, the criteria that are defined, such as informed consent, confidentiality and privacy, seem not to be much of an issue to research where there is a reciprocal relation between the researcher and the researched (Christians 2005; Ferguson 1993). In research that has broken down the walls between subject and researcher and which understands research subjects as participating agents carrying knowledge and interpreting their own life worlds, ethical concerns of justice, fairness and moral actions go far beyond rigid sets of rules and guidelines. In some cases, researchers have to be aware of the fact that obtaining certain information would automatically turn them into 'bearers of secrets' - as being in possession of information that could prove to be very harmful for the respondents, sometimes without even being aware of it.

Most of the ethical guidelines available for migration scholars refer to very general regulations, such as confidentiality and privacy, the assessment of benefit versus harm, informed consent and the duality of roles (Knapik 2002). They still bear the hallmarks of medical research and life science. In this chapter we argue that general ethical guidelines and recommendations are important but often not enough. There are a number of ethical choices that need to be made when reaching more sensitive areas for which the general guidelines may not have an answer.

\subsection{How to Build Up Trust in a Context of Mistrust?}

A prerequisite for every successful qualitative interview is the building-up of a trustful relationship between interviewer and narrator. 'Trust' is of particular importance when researching a sensitive topic. At the same time, building up trust between the researcher and the researched when the topic is sensitive is difficult. For a number of reasons, those engaged might not be willing to talk about their past experiences or current situation with an unknown person like a researcher who, if not an insider, can hardly relate to the narrators' experiences. Throughout our own research process it became evident that, for our respondents - who had all had to either flee from dangerous situations or migrate irregularly - trust and mistrust represented decisive factors accompanying them throughout the whole migration process, from the time 
before departure until the time of arranging for a life at the point of arrival. Therefore, trust and mistrust have a significance that is hard to compare with the standards which an 'outsider' interviewer is usually acquainted with. As a consequence, anyone who asks questions about the interviewees' lives and, more specifically, about their migration process, may be approached with suspicion and show great reluctance to share certain crucial information.

In order to carry out a successful irregular migration process, a migrant depends on being able to trust the various agents, be they travel facilitators, passport brokers or other brokers. As the smuggling process is dangerous in many ways, the person concerned is forced to trust different agents when 'en route'. In a continuous balancing act, migrants time and again have to decide whether to trust a person or not; sometimes they even find themselves fully at the mercy of strangers (e.g. cotravellers, accommodating persons, border officials, smugglers, etc.). Thus, trust and mistrust are key factors in migrants' survival strategy, and can actually be the difference between life and death.

'Mistrust' and 'suspicion', however, play an important role with regard not only to the migrants but also to all actors involved. Migrants themselves are also mistrusted and often intensively questioned from many sides (Hynes 2003). En route, mutual mistrust between smuggling agents and their clients is a widely observed phenomenon. Secrecy, too, is a very important tool in order to keep 'control' over the clients of smugglers (Bilger et al. 2006). With the increase of mobile technology-in particular GPS, messenger services and social media-the control over migrants by smugglers has changed to some degree as technology allows for more independence for migrants. Information on smugglers is shared quickly between migrant networks but, in certain contexts, migrants may also travel (parts of the journey) on their own (Optimity Advisors, ICMPD and ECRE 2015; Zijlstra and van Liempt 2017).

On arrival, asylum hearings are important contexts in which a culture of suspicion is created because migrants are intensively questioned from many sides (see also Hynes 2003). Furthermore, migrants often find themselves isolated, discriminated and excluded from society in the country of arrival and, subsequently, they often mistrust their environment. Researchers are not exempt from this setting. On the contrary, already the term 'research' in itself might be something that raises suspicion among research participants (see also Smith 2002). Although it is crucial to understand why and how individuals develop mistrust towards certain groups of persons or specific situations, unfortunately this fact is often not taken into account while doing research among these specific groups (Hynes 2003).

However, how do you build up trust if you do not know what or whom your respondents are actually mistrusting? Besides agreed ethical standards of guaranteeing anonymity and confidentiality, building up trust requires researchers to understand the situation in which respondents find themselves. It also requires researchers to establish personal contacts with possible respondents. As well as the use of open interviews, informal settings in which respondents feel more comfortable, can talk freely about their experiences and do not feel urged to touch upon topics they do not want to talk about, might help to gain their trust. 
The private surroundings in which most of our interviews were carried out helped to provide the necessary privacy and trust in a safe and suitable atmosphere. Singleperson settings were considered the most appropriate when narrators worried about losing their anonymity with others being around. Expressions like 'Don't talk to the others about it!' reflected their fears. Small-group settings proved to be the most appropriate for couples, families or groups of friends. In such cases, one of the narrators would usually be more outspoken than the others, marking the beginning of the conversation, which made it easier for the others to follow this example. For reasons of privacy, too, in many cases, we decided not to tape-record the conversation. For the same reason, in some cases only fragmentary notes were taken during the conversation; however, these notes (including interviewers' memories of the conversation) were written up immediately after each interview.

In our research, every effort was made to keep the interview as informal as possible and to have the comparatively long conversation-like interview of 90-180 min in places atypical of the interview situations in which respondents had previously found themselves. A quiet environment was chosen, if possible one suggested by the narrators themselves, such as in their home or places of accommodation, NGOs, coffee-house, school, etc. Interviews were strictly based on the voluntary participation of the respondents and were carried out either with one individual or in small group settings consisting of a maximum of two or three persons, depending on the respective narrators' readiness to talk. If necessary, some individuals were interviewed several times. The method we followed was the 'problem-centred' interview, which aims 'to gather objective evidence on human behavior, as well as on subjective perceptions and ways of processing social reality' (Witzel 2000: 1). To maintain the focus, a basic interview schedule containing major topics to be touched upon during the interview was applied; this gave the respondent an opportunity to explore his or her experiences with as little encumbrance or interference by the interviewer as possible.

In the preparatory phase, interviewers were trained to carry out 'embedded questioning' (Cornelius 1982: 396). Narrators were encouraged to depict whatever came to mind with regard to the topic of interest. In so doing, the narrators were in a position to stress and highlight selected facts of vital importance to them, portray them accordingly and determine the order in which the topics were discussed. Providing this freedom turned out to be crucial, taking into consideration that many respondents, due to the situation they were currently in, had been exposed to continuous and sometimes intimidating questioning by administrative bodies, the police, the asylum authorities, medical doctors, etc. and, consequently, might simply be tired of talking about themselves or might be induced to share their experiences only as and when they felt in control of their own definitions of the self and their current situation. In addition, most interviews were carried out in the respondent's first language and transcripts and/or protocols were then translated afterwards. 


\subsection{Triggering Memories in an Ethical Way}

Another important aspect in this context is the problem of the triggering of painful memories during an interview and the issue of how to deal with the situation when painful biographical events are recalled which, even unintentionally, open or reopen a hidden psychological wound. In this case, the researcher's role becomes even more difficult as the interview can have a profound effect on the well-being of the narrator, who had perhaps never mentioned these issues before (Knapik 2002). Research projects in which counselling tools were used taught us that emotional release is greatly helped by a process that begins by simply taking turns of equal length to listen to each other (van den Anker 2006). The open character of the interviews also the narration stream to be more flexible, as it is left to the narrator to decide which topics to explore more and which to touch on less. Malkki (1995) argues that building up trust may, in the first place, be related to the researcher's willingness to leave some 'stones unturned' and to learn not to probe further when this is clearly not wanted.

For those interviews which we did not do ourselves, the interviewers were carefully selected and specifically trained before going into the field. Great attention was paid to the choice of location - which was left up to the narrators to chooseand to other aspects that might have an impact on the atmosphere of such a setting. In addition, every single interview was reviewed in terms of potentially difficult dynamics and used as a basis for the improvement of subsequent talks.

\subsection{Accessing the Research Population}

The decision on whom to interview is not only determined by methodological considerations relevant to the respective sample logic or of questions relating to accessing a somewhat hard-to-reach population. Interviewing migrants who can talk about their irregular migration process from their own experience also raises a number of ethical considerations when these persons' residential status is of a 'fragile' or temporary nature (e.g. such as during the asylum determination process or when remaining undocumented-see also Duvell et al. 2008). For fear of being 'detected' or identified, these migrants might be particularly hesitant in talking about their personality or their (irregular) migration process. In our research, asylum-seekers, for example, were theoretically comparatively easy to locate as they were usually housed by the public care system. However, while still in the asylum determination process, their 'insecure' legal status often deterred them from participating in the research project. Besides, the fresh memory of the official interview during the asylum procedure, we assumed, could have impacted the interview process considerably. We therefore also included persons who were not going through the asylum procedure at the time of the research but who had already obtained refugee or any 
other legal status, were rejected asylum-seekers or were smuggled migrants living undocumented in the host country. In this field, researchers need to pay particular attention to how they gain access to research participants and whether their methods are ethically correct. Identifying research participants as belonging to a certain target group might actually harm them in terms of the quality and duration of their future residence in the country (see also Dahinden and Efionayi-Mäder 2009). Working with undocumented immigrants requires extra care.

Aside from established methods of making contact with research participants such as snowball sampling (Atkinson and Flint 2001), using gate keepers (Bloch 1999) or site selection strategies, another potential source of contacts is the members of the research team themselves. In all of our projects, researchers worked together with bi- or multilingual interviewers who had personal contacts with potential respondents, friends and relatives who met the selection criteria of the target group (migrants who had been smuggled) or who could make direct contact with individuals from the target group. In this way, the interviewers themselves become 'part of the immigrant kinship-friendship network in the research community' (Cornelius 1982: 387). Despite methodological risks particularly in regard to objectivity (Bloch 1999), the advantages in terms of access and openness were considered to be more important for our research. Ellis and MacGaffey (1996) point out that, when doing research into groups who are difficult to access and where there is a high degree of suspicion towards the 'outsider', it makes much more sense to involve a collaborating 'insider' in order to gain access to these networks. The 'insider' is also part of the network and is in possession of extended personal contacts within the researched population. Co-nationals or co-ethnics might find it easier to empathise with the narrator's position and be more likely to build up trust and thus identify risks that might negatively affect research participants, either when contacting the interviewees or during the interview itself. This became obvious, during the course of our interviews, in expressions like 'You know how it is...', 'As you know, we...' and 'You might understand why...' used by several individuals when talking to co-national or co-ethnic interviewers.

However, sharing the same ethnic background may also make the respondent somewhat suspicious because such interview situations run the risk of touching upon sensitive political, social or cultural issues of which the individual interviewer may not be aware. It might be precisely the 'outside' position of the researcher that induces the narrator to speak more freely about certain aspects of his or her experience which are usually not easily discussed within their own community. The interviewer's position as an 'outsider' might also prove to be an advantage in situations where a certain suspicion towards the narrator's co-nationals or co-ethnics is to be expected.

In our research, for example, one West African woman was not willing to talk with the co-ethnic interviewer, since she worried that sharing her experiences would be seen as betrayal and information revealed would be spread in her own community. All our interviewers were therefore carefully prepared to deal with possibly emerging problems of bias and confidentiality. Self-reflection and reflections of the general interview atmosphere were of specific importance. Furthermore, all 
interviews carried out were discussed again and questions raised by the person analysing the interview in order to avoid misinterpretation. Indeed, several times it turned out that some aspects were taken for granted by the interviewer, who did not ask for any explanation. In such cases, it was very useful to have the possibility to go back to the respondents and ask for clarification.

\subsection{Why Did Migrants Participate in Our Research?}

We assumed that many of our participants would not—or would not easily — speak about their experiences during their migration process in detail due to their vulnerable position. Surprisingly, they did not refuse because they did not want to talk about the human smuggling process as such. The decision not to participate was instead related to the fact that these persons had been questioned many times already about their migration process and were tired of talking about it. This was especially the case for those we had contacted through organisations or other gatekeepers. Indeed, in line with the above-mentioned difficulties with regard to contacts chosen by gatekeepers, in our research some potential partners were being approached for the third or fourth time, either by journalists or by researchers. Reduced to the status of research subjects, they were just tired of speaking about their migration history over and over again. This hesitation was supported by the fact that, during our first fieldwork period (2002-2004), 'asylum' was highly politicised, both in Austria and in the Netherlands, as more restrictive legal changes were in preparation. More recent fieldwork in 2015 was conducted by Zijlstra and van Liempt in the context of the current 'refugee crisis', with an even wider shared concern than before that participation in research may lead to actions against smugglers and thus restrict access to smugglers' services (Optimity Advisors, ICMPD, ECRE 2015: 18).

Nevertheless, more than 100 men, women and families who had been in contact with human smugglers at some time during their migration process were actually interested in talking about their experiences with us. With the aim of better understanding their narration strategies, the question of why they actually had decided to participate was of specific importance. It was assumed that particular expectations in terms of benefits if they participated might be reflected in their respective narration streams. To understand these expectations was considered vital in order to detect certain biases in the narration strategy, which could then explain why certain aspects might have been specifically amplified while others were not touched upon.

Asked about their participation, the answers provided were manifold. Whereas, for some, the tense political climate at the time of conducting interviews deterred their participation, for others, it was exactly this very climate that encouraged them to take part. Participation was envisaged by arguing that they would like to make their story public (through research or journalism) so that the wider community would know about what was actually going on in the migrants' countries and why they had come to Europe. In these cases, the narrator would try his/her best to present the migration process in the way that would best draw attention to their difficult 
lives. While some had decided to participate due to the presumed scientific relevance of the research, for others the interview meant a social event more than anything else. This was especially true for participants who felt lonely and liked to chat about their lives. Many respondents also expressed their surprise that an 'outsider' was interested in their situation; interestingly, the interviewer simply showing interest in the migrants' biographies turned out to be in complete contrast to the official interviews to which they had been subjected. In addition, some narrations were likely to be amplified by strategies of self-promotion. The most obvious example in this sense was, for example, the outspoken desire to become very close friends or even marriage partners with the interviewers.

Others asked for legal advice. In these cases, the interview was clearly centred around topics concerning the asylum system and applications or 'illegal' stays. Some people even presented the tons of paperwork and correspondence they had had with the official authorities and asked the researchers for opinions on their case. Thus, it was particularly important to be very open, right from the beginning, about the limits the migrants could expect when participating. In every single case and with every individual concerned we made sure that we could refer them to qualified experts. Researchers in this field must be aware that the relation between the researcher and the respondent, even if trustful and close, is not equal and is clearly influenced by inequalities of rights, legal and economic position, gender and/or psychological position. Sometimes, researchers might deliberately be provoked on certain topics in order for the migrants to determine what the reactions of 'native' citizens might be. Like the young man who played with his 'fake' identity by showing a forged identity card: '...don't you believe me, don't you think I am a British citizen? Why not? It could be possible, couldn't it?'

As Glazer (1982) notes, participants have their own reasons for agreeing to be interviewed and many are able to set limits on what information they provide. Participants had their own reasons for participating; talking about their lives was a vital part of reality for many participants who had to present themselves repeatedly in certain ways in order to be able to survive or to reach their goals. Nevertheless, when it came to more personal aspects beyond their 'official identity', it became more difficult, just as Cowles notes: 'Even those subjects [sic] who appear to be open in their responses to the research activity may become, in the midst of their participation, increasingly hesitant or evasive when they realize that they are revealing information that they would rather not have exposed' (Cowles 1988: 171). Thus, while a lack of respect for someone's dignity might also be expressed by being overprotective, on the other hand every effort should be made to provide the necessary space for research participants to present their lives in their own way. In this regard, ensuring an unstructured, conversation-like interview environment in which participants could talk freely, 'embedded questioning' and the private surroundings in which the interviews took place all proved to be very helpful in more than just a technical sense. 


\subsection{Official and Unofficial Representations of the Self}

When certain migrants give accurate information about themselves and their travels, this might endanger their current position and future options. In migration research, the topic of (re)presentation is most prominently discussed in studies on asylum migration. Although extensive empirical evidence shows that refugees perceive their identity to be very different to that ascribed to them by the institutionalised refugee determination system, surprisingly little is known about how refugees present themselves within this context. Zetter (1991) raises an interesting point by arguing that refugees may be interested in the label they are given by others. They may also object to it. In recognising that others often categorise them negatively or incorrectly, he argues that it is exactly this labelling which, on the other hand, entitles them to certain rights. Presenting their case in line with what immigration officers expect to hear can thus be beneficial for them. These aspects, however, do not concern refugees or asylum-seekers only. Migrants who had moved irregularly, who had used smugglers to migrate or, in particular, who continue to stay undocumented in the country of destination, have good reasons to present and represent themselves in a certain way in order to be able to organise their survival, e.g. in order to find work, get access to health care, etc. These conditions influence the way in which migrants present themselves and may lead to a constant adaptation of narrations according to the requirements imposed on them in a given situation. Often migrants who had moved irregularly and/or were asylum-seekers not only need to organise the biographical aspects in a predetermined way but, consequently, have to shift between various representations. Memory has to revert from an 'unofficial' identity to an 'official' one.

Thus, smuggled migrants, who run the risk of being interviewed by officials (police, medical doctors, etc.) at any time, might be biased in an interview situation and therefore might choose to provide only scarce information or information of only limited use. Most obviously, narrators would highlight certain biographical aspects while other aspects (those which might have negative consequences for their lives if openly revealed) might either not be touched upon in detail, not revealed at all or adapted accordingly. This situation calls for an even broader focus by analysing not only what is presented and what is not presented but also how migrants present themselves and their individual migration journey. In order to analyse the data collected, it seemed useful to understand more about why and when our respondents could possibly have kept certain details back or adapted their narratives.

This specific dilemma calls for a very accurate and ethically sound approach by the researchers, because it could destroy the trust that was built up with respondents. Several participants confirmed the need to talk carefully about their lives. The Dublin regulations may serve as a good example of how a certain legal regulation may have an influence on a narrated biography. Without some modifications or secrecy in descriptions of the route or of the specific countries through which the migrant had transited, he or she would not be allowed to stay in the country of arrival, but would be sent back to the 'safe third country' through which he or she had passed. This may explain why, often, only little or no detailed information is to be found on the final 
part of the migration trajectory collected by the official immigration authorities. As a consequence, explanations on the route may be similar to the following, which originated from a database containing information on first asylum hearings:

I came with a direct flight to an unknown place, and then I was brought with a white car of an unknown type to an unknown place. I don't know what countries we passed. I was dropped at an unknown place, somewhere and now I am here.

Details on the routes taken were sometimes kept back in our interviews, toointerestingly, usually for other reasons, just like this Eritrean woman who shared her worries with us:

I won't tell you the exact name of the mountain where we were hiding; it is a famous place, you might want to know about it, but there are more people to follow and I do not want to betray them.

At the time of our conversation, this woman was no longer going through the asylum procedure, so there was no need for her to hide information concerning the route she had in order not to jeopardise her potential admission; nevertheless, she still had good reasons for holding back this information. Taking into account migrants' social realities helps to place the information revealed in context. However, researchers must also be aware that, in their conversations, interviewees may recall the situation in which they found themselves previously; they may thus have built up a certain expertise in presenting themselves in particular ways.

This active use of different ways to present their identity and biographies can have severe complications when analysing the data. They might offer information which shows clearly that the event cannot have happened as suggested. 'We were landing with the boat in Milan', as stated by a male respondent from Guinea, cannot have happened simply because Milan is not located close to the sea. However, there might also be information offered which is much harder to identify or where, for various reasons, some details are simply not clearly remembered not considered relevant by the narrator. In order to be able to deal with this kind of information, a first step is to reflect on why certain information is, or is not, provided in this way: did the person just not remember it clearly or did he/she confuse the location with another through which he/she transited? Was he/she instructed by someone to give this answer? Is it the easiest way not to disclose anything that might be difficult to talk about? All these questions were discussed at length both within the research team and with respondents, if the dynamics of the conversation allowed. In any case, researchers should be prepared to not receive the answers to such questions but to revert instead to a reflective analysis process.

\subsection{Analysing Different Representations}

In a second step, the issue then is how this kind of information should be valued and processed: should we just ignore the details of the story? Should we take the whole narration as a 'constructed' story? Should such information just be taken as 
it was stated or should the meaning behind it be questioned? We do not have a clear and universal answer to such questions but it is definitely a personal and ethical consideration which needs to be considered and balanced for every single case. In this regard, the key to the analysis is to understand that information is actually provided under certain circumstances and, supposedly, with particular intentions or expectations by the respondents. In our case, interviewers were instructed to also critically reflect on their own performance, as well as on the specific circumstances of the particular interview. This could have had an effect on the information that was provided and on the way in which it was offered. Examples of this are the duration of the interview, the description of the place in which the interview was carried out, the general atmosphere, those present, interruptions and disturbances, the impression of the emotional state of the narrator, impressions of how the interview progressed and the interpersonal interaction, obvious particularities in the interview, etc.).

With regard to the analysis and evaluation, it is important to be aware of the specific political framework within which certain migrants are navigating in order to understand their potential narration strategies. Revealing certain details or drawing conclusions without critically reflecting on them not only provides a distorted picture in a wider context but may also have negative consequences for the participants. Thus, researchers should be aware of their power over the distribution of knowledge. Taking basic ethical implications into account is not a straightforward process but a balancing act, with difficult choices to be made. In our view, the increased attention given to research involving vulnerable persons has not yet been adequately translated into corresponding publications on ethical challenges in the study of migration. The relative scarcity of these publications reflects the dilemma caused by the multidisciplinary nature of migration studies; however, it may also reflect reservations about emphasising the fact that there are serious dilemmas related to empirical research with vulnerable migrants (Bilger and van Liempt 2009).

In our specific research area, which touches upon several levels of irregularity, the problem of dealing with anonymity, confidentiality and privacy may concern not only research participants but also those, such as gate-keepers, supporting them as well as any other person in contact with potential participants. It should be recognised that insensitive treatment in regard to 'privacy' can potentially harm not only individuals but also groups or even a community as a whole. In our study, the fact that a failure to ensure confidentiality may cause harm to the reputation of the research community if it became apparent that insensitive interviewing by the researcher might have consequences for other researchers. Some potential participants and gate-keepers refused to participate, referring to the bad experiences they had previously had with researchers interested in their lives-we were informed that, after information from their interviews had been processed, participants did not find that their input was reflected in the write-up by the research team. On the contrary, research results also referred to in the media and policies had, at the very least, cast a poor light on the interviewees and their communities. This last aspect is directly linked to the ethical rule of 'balancing the harm and the benefits', where it is the researcher's obligation to strive to 
'minimise harm' and 'maximise benefits' for their research subjects. Thus, when carrying out research on a topic like human smuggling, the more sensitive aspect is the striving to minimise harm.

Information gathered in interviews can quite easily be used by third parties, be it against the respondents themselves or against any other actors involved. Thus, it should be recognised that researchers and participants alike may not always see the harm and benefits of a research project or may not see it in the same way. This therefore places extra demands for accuracy and sensitivity on researchers, who must try to understand the views of the potential or actual research subjects from their perspective. This is of particular importance in conversation-like interviews as, in such settings, the researcher is actively seeking to obtain very private information. Thus, the principle of 'informed consent' turns out to be rather complex, as the potential effects of participating are not easily predictable (see also Bilger and van Liempt 2009). Of course, participants must have the right to make an informed decision and to hear a full explanation of the research project in order for them to then decide whether or not to participate. Interviewees should be able to stop the interview whenever they want and our interview technique was clearly aiming for participants to present their own interpretation of specific events and to reveal only what he or she wanted to at any particular moment. Contact details were also left for everybody in case they wanted to reverse their participation and back out from the project, even after the interview had taken place. However, already at an early stage of data collection we realised that asking interviewees to sign a consent form was counterproductive to our efforts to build up trust. Why are we, the researchers, asking for them to sign a document? What could this document be about? We did guarantee anonymity, but did not ask people to sign a form which would require them to reveal their name and sign the form.

\subsection{Conclusion}

Qualitative research with smuggled migrants proved that incorporating their experiences was not only feasible but was considered important for building up knowledge of a topic on which insider knowledge was largely missing. Precisely by exploring the knowledge, experiences, evaluations and strategies of those who had themselves been involved were we able to nuance stereotypical ideas and common knowledge on human smuggling processes. This also seemed to be reflected in the alleged beliefs about who can provide information and who cannot, who has a say and who has not. Such an approach, however, entails very particular methodological and ethical considerations and demands specific sensitivity and accuracy. There are generally three kinds of relationship where the failure to safeguard ethical guidelines may cause harm: (1) to the relationship of trust between the researcher and the interviewee, (2) to other individuals or groups and/or (3) to the reputation of the research community. 
Existing ethical guidelines are formalistic recommendations which are often not enough of a guideline for the difficult choices that need to be made in research with vulnerable migrants. During our fieldwork, for example, we realised that a narrative may not simply be the story of a life but rather a conscious or unconscious strategy for self-presentation and a legitimisation of an interviewee's projections for the future. Researchers in this field need to be aware that, apart from an often-traumatic experience, external structural factors such as the respective migration and integration policy framework, have an impact on how vulnerable migrants present and represent themselves and their migration journey in an interview situation. It is difficult for researchers to know how irregularity in migration processes is influencing the individual narratives and how to deal with these findings in an ethical way.

While discussing ethics, it is vital to acknowledge that they are not an 'afterthought' (Miller and Bell 2012) or something that only needs to be considered at the moment when the research proposal is evaluated. Ethical issues need to be raised and reflected upon from the conceptualisation of the research until the placement of the results in the public arena (Glazer 1982). They should be an ongoing part of research and we hope that this chapter will serve as a starting point for such a discussion.

\section{References}

Ahmad, A. N. (2011). Masculinity, sexuality and illegal migration: Human smuggling from Pakistan to Europe. Farnham: Ashgate.

Antonopoulos, G. A., \& Winterdyk, J. (2006). The smuggling of migrants in Greece: An examination of its social organization. European Journal of Criminology, 3(4), 439-461.

Atkinson, R., \& Flint, J. (2001). Accessing hidden and hard-to-reach populations: Snowball research strategies, Social Research Update, Issue 33. Guildford: University of Surrey. Accessed 8 May 2017.

Bhabha, J. (2005). Human smuggling, migration and human rights. Geneva: The International Council on Human Rights Policy Working Paper. Online at: http://www.ichrp.org/files/ papers/137/122_Bhabha.pdf. Accessed 11 December 2017.

Bilger, V., \& van Liempt, I. (2009). Introduction. In I. Van Liempt \& V. Bilger (Eds.), The ethics of migration research methodology: Dealing with vulnerable immigrants (pp. 1-24). Eastbourne: Sussex Academic Press.

Bilger, V., Hofmann, M., \& Jandl, M. (2006). Human smuggling as a transnational service industry. International Migration, 44(4), 59-93.

Bloch, A. (1999). Carrying out a survey of refugees: Some methodological considerations and guidelines. Journal of Refugee Studies, 12(4), 367-383.

Chin, K. L. (1999). Smuggled Chinese: Clandestine immigration to the United States. Philadelphia: Temple University Press.

Christians, C. G. (2005). Ethics and politics in qualitative research. In N. K. Denzin \& Y. S. Lincoln (Eds.), Handbook of qualitative research (3rd ed., pp. 139-164). Thousand Oaks: Sage.

Cornelius, W. (1982). Interviewing undocumented migrants: Methodological reflections based on fieldwork in Mexico and the US. International Migration Review Special Issue: Theory and Methods in Migration and Ethnic Research, 16(2), 378-411.

Cowles, K. (1988). Issues in qualitative research on sensitive topics. Western Journal of Nursing Research, 10(2), 163-179. 
Dahinden, J., \& Efionayi-Mäder, D. (2009). Challenges and strategies in empirical fieldwork with asylum seekers and migrant sex workers. van Liempt I, V. Bilger The ethics of migration research methodology. Dealing with vulnerable immigrants (98-117). Eastbourne: Sussex Academic Press.

Donato, K. M., Wagner, B., \& Patterson, E. (2008). The cat and mouse game at the Mexico-U.S. border: Gendered patterns and recent shifts. International Migration Review, 42(2), 330-359.

Doornbos, N. (2003). De papieren asielzoeker. Institutionele communicatie in de asielprocedure. Nijmegen: Gerard Noodt Instituut.

Duvell, F., Triandafyllidou A., \& Vollmer, B. (2008). Ethical issues in irregular migration research. Oxford: COMPAS, Deliverable 2 of the research project CLANDESTINO, Undocumented Migration: Counting the Uncountable. Data and Trends Across Europe.

Ellis, S., \& MacGaffey, J. (1996). Research on sub-Saharan Africa's unrecorded international trade. Some methodological and conceptual problems. African Studies Review, 39(2), 19-41.

Ferguson, D. (1993). Something a little out of the ordinary: Reflections on becoming an interpretivist researcher in special education. Remedial and Special Education, 14(4), 35-43.

Gallagher, A. (2002). Trafficking, smuggling and human rights: Tricks and treaties. Forced Migration Review, 12(January), 25-28.

Glazer, M. (1982). The threat of the stranger: Vulnerability, reciprocity and field-work. In J. Sieber (Ed.), The ethics of social research: Fieldwork, regulation and publication (pp. 49-70). New York: Springer.

Herman, E. (2006). Migration as a family business: The role of personal networks in the mobility phase of migration. International Migration, 44(4), 191-230.

Hynes, T. (2003). The issue of 'Trust' or 'Mistrust' in research with refugees: Choices, caveats and considerations for researchers, Working Paper No. 98. Geneva: UNHCR.

Knapik, M. (2002, July 5-17). Ethics in qualitative research: Searching for practice guidelines. Paper presented at the symposium 'Linking Research to Educational Practice II', University of Calgary, Calgary.

Lee, R. M. (1993). Doing research on sensitive topics. London: Sage.

Liamputtong, P. (2007). Researching the vulnerable. A guide to sensitive research methods. London: Sage.

Malkki, L. (1995). Purity and exile. In Violence, memory and national cosmology among Hutu Refugees in Tanzania. Chicago: University of Chicago Press.

Mauthner, M., Birch, M., Jessop, J., \& Miller, T. (2012). Ethics in qualitative research. 2nd Edition. London: Sage.

Miller, T., \& Bell, L. (2012). Consenting to what? Issues of access, gate-keeping and 'informed' consent. In M. Mauthner, M. Birch, J. Jessop, \& T. Miller (Eds.), Ethics in qualitative research. 2nd Edition. (pp. 53-69). London: Sage. https://uk.sagepub.com/en-gb/eur/ ethics-in-qualitative-research/book237572

Morrison, J., \& Crosland, B. (2001). The trafficking and smuggling of refugees: The end game in European Asylum Policy? Working Paper No. 39. Geneva: UNHCR. Online at: http://www. unhcr.org/research/working/3af66c9b4/trafficking-smuggling-refugees-end-game-europeanasylum-policy-john-morrison.html. Accessed 11 Dec 2017.

Nadig, A. (2002). Human smuggling, national security, and refugee protection. Journal of Refugee Studies, 15(1), 1-25.

Obokata, T. (2005). Trafficking of human beings as a crime against humanity: Some implications for the international legal system. International and Comparative Law Quarterly, 54(2), 445-457.

Optimity Advisors, ICMPD, ECRE. (2015). A study on smuggling of migrants: Characteristics, responses and cooperation with third countries. Final report. European Commission, DG Migration \& Home Affairs/European Migration Network, Brussels.

Peixoto, J. (2009). New migrations in Portugal: Labour markets, smuggling and gender segmentation. International Migration, 47(3), 185-210.

Salt, J., \& Stein, J. (1997). Migration as a business: The case of trafficking. International Migration, 35(4), 467-489. 
Sanchez, G. E. (2015). Human smuggling and border crossings. London: Routledge.

Schloenhardt, A. (2001). Trafficking in migrants: Illegal migration and organized crime in Australia and the Asia Pacific Region. Leiden: Nijhoff.

Schrover, M., Van der Leun, J., Lucassen, L., \& Quispel, C. (2008). Illegal migration and gender in a global and historical perspective. Amsterdam: Amsterdam University Press.

Smith, L. T. (2002). Decolonizing methodologies: Research and indigenous peoples. London: Zed Books.

Staring, R. (2004). Facilitating the arrival of illegal immigrants in the Netherlands: Irregular chain migration versus smuggling chains. Journal of International Migration and Integration, 5(3), 273-294.

UNODC. (2011). Smuggling of migrants. A global review and annotated bibliography of recent publications. New York: United Nations. Online at: https://www.unodc.org/documents/humantrafficking/Migrant-Smuggling/Smuggling_of_Migrants_A_Global_Review.pdf.

van den Anker, C. H. (2006). Re-evaluation counselling as a tool in combating ethnic discrimination and xenophobia. In C. H. van den Anker \& A. Apostolov (Eds.), Educating for peace and multiculturalism. A handbook for trainers (pp. 81-89). Warwick: The University of Warwick.

Van den Hoonaard, W. C. (Ed.). (2002). Walking the tightrope. Ethical issues for qualitative researchers. Toronto: University of Toronto Press.

Van Liempt, I. (2007). Navigating borders. Inside perspectives on the process of human smuggling into The Netherlands. Amsterdam: Amsterdam University Press.

Van Liempt, I., \& Sersli, S. (2013). State responses and migrant experiences with human smuggling: A reality check. Antipode, 45(4), 1029-1046.

Witzel, A. (2000). The problem-centred interview. Forum Qualitative Sozialforschung/Forum: Qualitative Social Research, 1(1). Online at: http://www.qualitative-research.net/fqs-texte/100/1-00witzel-e.htm. Accessed 8 May 2017.

Zetter, R. (1991). Labelling refugees: Forming and transforming a bureaucratic identity. Journal of Refugee Studies, 4(12), 39-62.

Zhang, S. X. (2008). Chinese human smuggling organizations: Families, social networks, and cultural imperatives. Stanford: Stanford University Press.

Zhang, S. X., Chi, K. L., \& Miller, J. (2007). Women's participation in Chinese transnational human smuggling: A gendered market perspective. Criminology, 45(3), 699-733.

Zijlstra, J., \& van Liempt, I. (2017). Smart(phone) traveling: Understanding the use and impact of mobile technology on irregular migration journeys. International Journal of Migration and Border Studies, 3(2/3), 174-191.

Open Access This chapter is licensed under the terms of the Creative Commons Attribution 4.0 International License (http://creativecommons.org/licenses/by/4.0/), which permits use, sharing, adaptation, distribution and reproduction in any medium or format, as long as you give appropriate credit to the original author(s) and the source, provide a link to the Creative Commons license and indicate if changes were made.

The images or other third party material in this chapter are included in the chapter's Creative Commons license, unless indicated otherwise in a credit line to the material. If material is not included in the chapter's Creative Commons license and your intended use is not permitted by statutory regulation or exceeds the permitted use, you will need to obtain permission directly from the copyright holder.

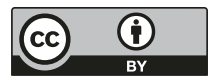

